\title{
Fixed and coupled fixed point theorems of omega-distance for nonlinear contraction
}

\author{
Wasfi Shatanawi ${ }^{1}$ and Ariana Pitea ${ }^{2 *}$
}

"Correspondence:

arianapitea@yahoo.com

2Faculty of Applied Sciences, University Politehnica of Bucharest,

313 Splaiul Independenţei, Bucharest, 060042, Romania

Full list of author information is

available at the end of the article

\begin{abstract}
In this paper we utilize the notion of $\Omega$-distance in the sense of Saadati et al. (Math. Comput. Model. 52:797-801, 2010) to construct and prove some fixed and coupled fixed point theorems in a complete $\mathrm{G}$-metric space for a nonlinear contraction. Also, we provide an example to support our results.
\end{abstract}

MSC: $47 \mathrm{H} 10 ; 54 \mathrm{H} 25$

Keywords: coupled fixed point; $\Omega$-distance

\section{Introduction}

The concept of G-metric space was introduced by Mustafa and Sims [1]. After that, many authors constructed fixed point theorems in G-metric spaces. In [2] and [3], common fixed points results for mappings which satisfy the generalized $(\varphi, \psi)$-weak contraction are obtained. In [4], the author proves a common fixed point theorem for two self-mappings verifying a contractive condition of integral type in $G$-metric spaces. In [5, 6] and [7], tripled coincidence point results for a mixed monotone mapping in G-metric spaces are established; also see [8]. Some common fixed point results for two self-mappings, one of them being a generalized weakly $G$-contraction of type $A$ and $B$ with respect to the other mapping, are stated in [9]. Fixed point theorems for mappings with a contractive iterate at a point are formulated in [10] and in [11]. Papers [12] and [13] refer to common fixed point theorems for single-valued and multi-valued mappings which satisfy contractive conditions on G-metric spaces. In [14] and [15], theorems from G-metric spaces are used to obtain several results on complete $D$-metric spaces. Various contractive conditions on G-metric spaces which lead to fixed point results are stated in [16]. Paper [17] deals with the existence of fixed point results in G-metric spaces. In [18], common fixed point theorems with $\phi$-maps on $G$-cone metric spaces are established. In [19], a general fixed point theorem for mappings satisfying an $\phi$-implicit relation is proved. Paper [20] states fixed point theorems for mappings satisfying $\phi$-maps in G-metric spaces. Mohamed Jleli and Bessem Samet [21] in their nice paper pointed out that the quasi-metric spaces play a major role to construct some known fixed point theorems in a $G$-metric space. For other recent results in G-metric spaces, please see [22-24].

The coupled fixed point is one of the most interesting subjects in metric spaces. The notion of coupled fixed point was introduced by Bhaskar and Lakshmikantham [25], and the notion of coincidence coupled fixed point was introduced by Lakshmikantham and Ćirić [26]. In recent years many authors established many nice coupled and coincidence 
coupled fixed point theorems in metric spaces, partial metric spaces and G-metric spaces. For some works on this subject, we refer the reader to [27-38].

\section{Preliminaries}

It is fundamental to recall the definition of $G$-metric spaces.

Definition 2.1 ([1]) Let $X$ be a nonempty set. $G: X \times X \times X \rightarrow X$ is called G-metric if the following axioms are fulfilled:

(1) $G(x, y, z)=0$ if $x=y=z$ (the coincidence);

(2) $G(x, x, y)>0$ for all $x, y \in X, x \neq y$;

(3) $G(x, x, z) \leq G(x, y, z)$ for each triple $(x, y, z)$ from $X \times X \times X$ with $z \neq y$;

(4) $G(x, y, z)=G(p\{x, y, z\})$ for each permutation of $\{x, y, z\}$ (the symmetry);

(5) $G(x, y, z) \leq G(x, a, a)+G(a, y, z)$ for each $x, y, z$ and $a$ in $X$ (the rectangle inequality).

Definition 2.2 ([1]) Consider $X$ to be a $G$-metric space and $\left(x_{n}\right)$ to be a sequence in $G$.

(1) $\left(x_{n}\right)$ is called a G-Cauchy sequence if for each $\varepsilon>0$, there is a positive integer $n_{0}$ so that for all $m, n, l \geq n_{0}, G\left(x_{n}, x_{m}, x_{l}\right)<\varepsilon$.

(2) $\left(x_{n}\right)$ is said to be $G$-convergent to $x \in X$ if for each $\varepsilon>0$, there is a positive integer $n_{0}$ such that $G\left(x_{m}, x_{n}, x\right)<\varepsilon$ for each $m, n \geq n_{0}$.

Now, we recall the definitions of coupled and coincidence coupled fixed points.

Definition 2.3 ([25]) Consider $X$ to be a nonempty set. The pair $(x, y) \in X \times X$ is called a coupled fixed point of the mapping $F: X \times X \rightarrow X$ if

$$
F(x, y)=x, \quad F(y, x)=y .
$$

Definition 2.4 ([26]) Let $X$ be a nonempty set. The element $(x, y) \in X \times X$ is a coupled coincidence point of mappings $F: X \times X \rightarrow X$ and $g: X \rightarrow X$ if

$$
F(x, y)=g x, \quad F(y, x)=g y .
$$

In 2010, Saadati et al. [39] utilized the notion of G-metric spaces to introduce the concept of $\Omega$-distance. Moreover, Saadati et al. [40] constructed some fixed point theorem in $G$-metric spaces by using the notion of $\Omega$-distance.

Definition 2.5 ([39]) Consider $(X, G)$ to be a $G$-metric space and $\Omega: X \times X \times X \rightarrow$ $[0,+\infty) . \Omega$ is called an $\Omega$-distance on $X$ if it satisfies the three conditions as follows:

(1) $\Omega(x, y, z) \leq \Omega(x, a, a)+\Omega(a, y, z)$ for all $x, y, z, a$ from $X$.

(2) For each $x, y$ from $X, \Omega(x, y, \cdot), \Omega(x, \cdot, y): X \rightarrow[0,+\infty)$ are lower semi-continuous.

(3) For each $\varepsilon>0$, there is $\delta>0$, so that $\Omega(x, a, a) \leq \delta$ and $\Omega(a, y, z) \leq \delta$ imply $G(x, y, z) \leq \varepsilon$.

The following lemma is very useful in this paper.

Lemma $2.1([39,40])$ Let $X$ be a metric space endowed with metric $G$, and let $\Omega$ be an $\Omega$-distance on $X .\left(x_{n}\right),\left(y_{n}\right)$ are sequences in $X,\left(\alpha_{n}\right)$ and $\left(\beta_{n}\right)$ are sequences in $[0,+\infty)$, with $\lim _{n \rightarrow+\infty} \alpha_{n}=\lim _{n \rightarrow+\infty} \beta_{n}=0$. If $x, y, z$ and $a \in X$, then 
(1) If $\Omega\left(y, x_{n}, x_{n}\right) \leq \alpha_{n}$ and $\Omega\left(x_{n}, y, z\right) \leq \beta_{n}$, for $n \in \mathbb{N}$, then $G(y, y, z)<\varepsilon$, and, by consequence, $y=z$.

(2) Inequalities $\Omega\left(y_{n}, x_{n}, x_{n}\right) \leq \alpha_{n}$ and $\Omega\left(x_{n}, y_{m}, z\right) \leq \beta_{n}$, for $m>n$, imply

$G\left(y_{n}, y_{m}, z\right) \rightarrow 0$, hence $y_{n} \rightarrow z$.

(3) If $\Omega\left(x_{n}, x_{m}, x_{l}\right) \leq \alpha_{n}$ for $l, m, n \in \mathbb{N}$ with $n \leq m \leq l$, then $\left(x_{n}\right)$ is a G-Cauchy sequence.

(4) If $\Omega\left(x_{n}, a, a\right) \leq \alpha_{n}, n \in \mathbb{N}$, then $\left(x_{n}\right)$ is a G-Cauchy sequence.

The following two sets are very useful to build our nonlinear contraction in this paper:

$$
\begin{aligned}
\Phi= & \{\varphi:[0,+\infty) \rightarrow[0,+\infty) \mid \varphi \text { is continuous, increasing, } \varphi(t)=0 \text { if and only if } t=0\}, \\
\Psi= & \{\psi:[0,+\infty) \rightarrow[0,+\infty) \mid \psi \text { is lower semi-continuous, } \\
& \psi(t)=0 \text { if and only if } t=0\} .
\end{aligned}
$$

For some works on fixed point theorems based on the above sets, see, for example, $[1,7$, 14-20, 23, 33-39, 41-44].

In the present paper, we utilize the concept of $\Omega$-distance and the sets $\Phi, \Psi$ to establish some fixed and coupled fixed point theorems. Also, we introduce an example as an application of our results.

\section{Main results}

In the first part of the section, we introduce and prove the following fixed point theorem.

Theorem 3.1 Let $(X, G)$ be a G-metric space and $\Omega$ be an $\Omega$-distance on $X$. Consider $\varphi \in$ $\Phi, \psi \in \Psi$ and $T: X \rightarrow X$ such that

$$
\varphi \Omega(T x, T y, T z) \leq \varphi \Omega(x, y, z)-\psi \Omega(x, y, z)
$$

holds for each $(x, y, z) \in X \times X \times X$.

Suppose that if $u \neq T u$, then

$$
\inf \{\Omega(x, T x, u): x \in X\}>0 \text {. }
$$

Then $T$ has a unique fixed point.

Proof Let $x_{0} \in X$ and $x_{n+1}=T x_{n}$ for each $n \in \mathbb{N}$. If there is $n \in \mathbb{N}$ for which $x_{n+1}=x_{n}$, then $x_{n}$ is a fixed point of $T$.

In the following, we assume $x_{n+1} \neq x_{n}$ for each $n \in \mathbb{N}$.

First we shall prove that $\lim _{n \rightarrow+\infty} \Omega\left(x_{n}, x_{n+1}, x_{n+1}\right)=0$.

For $n \in \mathbb{N}, n \geq 1$, we have

$$
\begin{aligned}
\varphi \Omega\left(x_{n}, x_{n+1}, x_{n+1}\right) & =\varphi \Omega\left(T x_{n-1}, T x_{n}, T x_{n}\right) \\
& \leq \varphi \Omega\left(x_{n-1}, x_{n}, x_{n}\right)-\psi \Omega\left(x_{n-1}, x_{n}, x_{n}\right) \\
& \leq \varphi \Omega\left(x_{n-1}, x_{n}, x_{n}\right) .
\end{aligned}
$$

$\varphi$ is a nondecreasing function, hence $\Omega\left(x_{n}, x_{n+1}, x_{n+1}\right) \leq \Omega\left(x_{n-1}, x_{n}, x_{n}\right), n \geq 1$. It follows that $\left(\Omega\left(x_{n}, x_{n+1}, x_{n+1}\right)\right)$ is a nondecreasing sequence, therefore there exists $\lim _{n \rightarrow+\infty} \Omega\left(x_{n}, x_{n+1}\right.$, $\left.x_{n+1}\right)=r \geq 0$. 
Taking $n \rightarrow+\infty$ in inequality (2) and using the continuity of $\varphi$ and the lower semicontinuity of $\psi$, we get

$$
\varphi r \leq \varphi r-\liminf _{n \rightarrow+\infty} \psi \Omega\left(x_{n-1}, x_{n}, x_{n}\right) \leq \varphi r-\psi r
$$

imposing $\psi r=0$, that is, $r=0$.

Analogously, it can be proved that $\lim _{n \rightarrow+\infty} \Omega\left(x_{n+1}, x_{n}, x_{n}\right)=0$ and also that

$$
\lim _{n \rightarrow+\infty} \Omega\left(x_{n}, x_{n}, x_{n+1}\right)=0
$$

The next step is to prove that $\lim _{m, n \rightarrow+\infty} \Omega\left(x_{n}, x_{m}, x_{m}\right)=0, m>n$.

By reductio ad absurdum, suppose the contrary. Hence, there exist $\varepsilon>0$ and two sequences $\left(n_{k}\right)$ and $\left(m_{k}\right)$ such that

$$
\Omega\left(x_{n_{k}}, x_{m_{k}}, x_{m_{k}}\right) \geq \varepsilon, \quad \Omega\left(x_{n_{k}}, x_{m_{k}-1}, x_{m_{k}-1}\right)<\varepsilon, \quad m_{k}>n_{k} .
$$

As $\lim _{n \rightarrow+\infty} \Omega\left(x_{n}, x_{n+1}, x_{n+1}\right)=0$, it follows

$$
\begin{aligned}
\varepsilon & \leq \Omega\left(x_{n_{k}}, x_{m_{k}}, x_{m_{k}}\right) \leq \Omega\left(x_{n_{k}}, x_{m_{k}-1}, x_{m_{k}-1}\right)+\Omega\left(x_{m_{k}-1}, x_{m_{k}}, x_{m_{k}}\right) \\
& <\varepsilon+\Omega\left(x_{m_{k}-1}, x_{m_{k}}, x_{m_{k}}\right) \rightarrow \varepsilon \quad \text { as } k \rightarrow+\infty .
\end{aligned}
$$

Therefore, $\lim _{k \rightarrow+\infty} \Omega\left(x_{n_{k}}, x_{m_{k}}, x_{m_{k}}\right)=\varepsilon$

On the other hand,

$$
\begin{aligned}
\varepsilon & \leq \Omega\left(x_{n_{k}}, x_{m_{k}}, x_{m_{k}}\right) \leq \Omega\left(x_{n_{k}}, x_{n_{k}+1}, x_{n_{k}+1}\right)+\Omega\left(x_{n_{k}+1}, x_{m_{k}}, x_{m_{k}}\right) \\
& \leq \Omega\left(x_{n_{k}}, x_{n_{k}+1}, x_{n_{k}+1}\right)+\Omega\left(x_{n_{k}+1}, x_{m_{k}+1}, x_{m_{k}+1}\right)+\Omega\left(x_{m_{k}+1}, x_{m_{k}}, x_{m_{k}}\right) .
\end{aligned}
$$

The contraction condition (1) yields

$$
\begin{aligned}
\varphi \Omega\left(x_{n_{k}+1}, x_{m_{k}+1}, x_{m_{k}+1}\right) & \leq \varphi \Omega\left(x_{n_{k}}, x_{m_{k}}, x_{m_{k}}\right)-\psi \Omega\left(x_{n_{k}}, x_{m_{k}}, x_{m_{k}}\right) \\
& \leq \varphi \Omega\left(x_{n_{k}}, x_{m_{k}}, x_{m_{k}}\right),
\end{aligned}
$$

so $\Omega\left(x_{n_{k}+1}, x_{m_{k}+1}, x_{m_{k}+1}\right) \leq \Omega\left(x_{n_{k}}, x_{m_{k}}, x_{m_{k}}\right)$, and relation (3) becomes

$$
\begin{aligned}
\varepsilon & \leq \Omega\left(x_{n_{k}}, x_{n_{k}+1}, x_{n_{k}+1}\right)+\Omega\left(x_{n_{k}+1}, x_{m_{k}+1}, x_{m_{k}+1}\right)+\Omega\left(x_{m_{k}+1}, x_{m_{k}}, x_{m_{k}}\right) \\
& \leq \Omega\left(x_{n_{k}}, x_{n_{k}+1}, x_{n_{k}+1}\right)+\Omega\left(x_{n_{k}}, x_{m_{k}}, x_{m_{k}}\right)+\Omega\left(x_{m_{k}+1}, x_{m_{k}}, x_{m_{k}}\right) .
\end{aligned}
$$

Letting $k \rightarrow+\infty$, we get $\lim _{k \rightarrow+\infty} \Omega\left(x_{n_{k}+1}, x_{m_{k}+1}, x_{m_{k}+1}\right)=\varepsilon$.

Having in mind the continuity of $\varphi$ and the lower semi-continuity of $\psi$, we obtain

$$
\varphi \varepsilon \leq \varphi \varepsilon-\liminf _{k \rightarrow+\infty} \Omega\left(x_{n_{k}}, x_{m_{k}}, x_{m_{k}}\right) \leq \varphi \varepsilon-\psi \varepsilon,
$$

which is impossible, since $\varepsilon>0$. 
It follows that $\lim _{m, n \rightarrow+\infty} \Omega\left(x_{n}, x_{m}, x_{m}\right)=0, m>n$.

In a similar manner, it can be proved that $\lim _{m, n \rightarrow+\infty} \Omega\left(x_{n}, x_{n}, x_{m}\right)=0, m>n$.

Consider now $l>m>n, l, m, n \in \mathbb{N}$. Since

$$
\Omega\left(x_{n}, x_{m}, x_{l}\right) \leq \Omega\left(x_{n}, x_{m}, x_{m}\right)+\Omega\left(x_{m}, x_{m}, x_{l}\right) \rightarrow 0
$$

as $l, m, n \rightarrow+\infty$, we conclude that $\lim _{l, m, n \rightarrow+\infty} \Omega\left(x_{n}, x_{m}, x_{l}\right)=0$. By Lemma 2.1, $\left(x_{n}\right)$ is a $G$-Cauchy sequence in the $G$-complete space $(X, G)$, so it converges to $u \in X$.

Suppose $u \neq T u$. Consider $\varepsilon>0$. As $\left(x_{n}\right)$ is a Cauchy sequence, there is $n_{0} \in \mathbb{N}$ such that

$$
\Omega\left(x_{n}, x_{m}, x_{l}\right)<\varepsilon, \quad \forall n, m, l \geq n_{0} .
$$

Thus

$$
\liminf _{l \rightarrow+\infty} \Omega\left(x_{n}, x_{m}, x_{l}\right) \leq \liminf _{l \rightarrow+\infty} \varepsilon=\varepsilon, \quad \forall n, m \geq n_{0} .
$$

From the lower semi-continuity of $\Omega$ in its third variables, we have

$$
\Omega\left(x_{n}, x_{m}, u\right) \leq \liminf _{l \rightarrow+\infty} \Omega\left(x_{n}, x_{m}, x_{l}\right) \leq \varepsilon, \quad \forall n, m \geq n_{0} .
$$

Considering $m=n+1$ in inequality (4), we get

$$
\Omega\left(x_{n}, x_{n+1}, u\right) \leq \varepsilon
$$

On the other hand, we have

$$
\begin{aligned}
0 & <\inf \{\Omega(x, T x, u): x \in X\} \\
& \leq \inf \left\{\Omega\left(x_{n}, x_{n+1}, u\right): n \geq n_{0}\right\}<\varepsilon
\end{aligned}
$$

which contradicts the hypotheses.

Therefore, $u=T u$ and hence $u$ is a fixed point of $T$.

We shall deal now with the uniqueness of the fixed point of $T$.

Suppose that there are $u$ and $v$ in $X$ fixed points of the mapping $T$.

It follows that

$$
\varphi \Omega(v, u, u)=\varphi \Omega(T v, T u, T u) \leq \varphi \Omega(v, u, u)-\psi \Omega(v, u, u),
$$

which is possible only for $\psi \Omega(v, u, u)=0$, that is, $\Omega(v, u, u)=0$.

Similarly, it can be proved that $\Omega(u, v, u)=0$.

According to the definition of an $\Omega$-distance, $\Omega(v, u, u)=0$ and $\Omega(u, v, u)=0$ imply $u=v$. Hence, $T$ has a unique fixed point.

Haghi et al. [45] in their interesting paper showed that some common fixed point theorems can be obtained from the known fixed point theorems; for other interesting article by Haghi et al., please see [46]. By using the same method of Haghi et al. [45], we get the following result. 
Theorem 3.2 Let $(X, G)$ be a G-metric space and $\Omega$ be an $\Omega$-distance on $X$. Consider $\varphi \in$ $\Phi, \psi \in \Psi$ and $T, S: X \rightarrow X$ such that

$$
\varphi \Omega(T x, T y, T z) \leq \varphi \Omega(S x, S y, S z)-\psi \Omega(S x, S y, S z)
$$

holds for each $(x, y, z) \in X \times X \times X$.

Suppose the following hypotheses:

(1) $T X \subseteq S X$.

(2) If $S u \neq T u$, then

$$
\inf \{\Omega(S x, T x, S u): x \in X\}>0 \text {. }
$$

Then $T$ and S have a unique common fixed point.

As consequent results of Theorem 3.1 and Theorem 3.2, we have the following.

Corollary 3.1 Let $(X, G)$ be a G-metric space and $\Omega$ be an $\Omega$-distance on $X$. Consider $\psi \in \Psi$ and $T: X \rightarrow X$ such that

$$
\Omega(T x, T y, T z) \leq \Omega(x, y, z)-\psi \Omega(x, y, z)
$$

holds for each $(x, y, z) \in X \times X \times X$.

Suppose that if $u \neq T u$, then

$$
\inf \{\Omega(x, T x, u): x \in X\}>0 \text {. }
$$

Then T has a unique fixed point.

Corollary 3.2 Let $(X, G)$ be a G-metric space and $\Omega$ be an $\Omega$-distance on $X$. Consider $\psi \in \Psi$ and $T, S: X \rightarrow X$ such that

$$
\Omega(T x, T y, T z) \leq \Omega(S x, S y, S z)-\psi \Omega(S x, S y, S z)
$$

holds for each $(x, y, z) \in X \times X \times X$.

Suppose the following hypotheses:

(1) $T X \subseteq S X$.

(2) If $S u \neq T u$, then

$$
\inf \{\Omega(S x, T x, S u): x \in X\}>0 \text {. }
$$

Then $T$ and S have a unique common fixed point.

In the second part of the section, we introduce and prove the following coincidence coupled fixed point theorem.

Theorem 3.3 Consider $(X, G)$ to be a G-metric space endowed with an $\Omega$-distance called $\Omega$. Let $F: X \times X \rightarrow X$ and $g: X \rightarrow X$ be two mappings with the properties 
$F(X \times X) \subseteq g X$, and $g X$ is a complete subspace of $X$ with respect to the topology induced by $G$.

Suppose that there exist $\varphi \in \Phi$ and $\psi \in \Psi$ such that

$$
\begin{aligned}
& \varphi\left(\Omega\left(F(x, y), F\left(x^{*}, y^{*}\right), F\left(z, z^{*}\right)\right)+\Omega\left(F(y, x), F\left(y^{*}, x^{*}\right), F\left(z^{*}, z\right)\right)\right) \\
& \quad \leq \varphi\left(\Omega\left(g x, g x^{*}, g z\right)+\Omega\left(g y, g y^{*}, g z^{*}\right)\right)-\psi\left(\Omega\left(g x, g x^{*}, g z\right)+\Omega\left(g y, g y^{*}, g z^{*}\right)\right)
\end{aligned}
$$

for each $(x, y),\left(x^{*}, y^{*}\right),\left(z, z^{*}\right) \in X \times X$.

Additionally, suppose that if $F(u, v) \neq$ gu or $F(v, u) \neq g v$, then

$$
\inf \{\Omega(g x, F(x, y), g u)+\Omega(g y, F(y, x), g \nu): x, y \in X\}>0 .
$$

Then $F$ and $g$ have a unique coupled coincidence point $(u, v)$, with $F(u, v)=g u=g v=$ $F(v, u)$.

Proof Let $\left(x_{0}, y_{0}\right) \in X \times X$. Having in mind that $F(X \times X) \subseteq g X$, for each $n \in \mathbb{N}$, there is a pair $\left(x_{n+1}, y_{n+1}\right) \in X \times X$ such that

$$
g x_{n+1}=F\left(x_{n}, y_{n}\right), \quad g y_{n+1}=F\left(y_{n}, x_{n}\right) .
$$

First, we prove that

$$
\lim _{n \rightarrow+\infty} \Omega\left(g x_{n}, g x_{n+1}, g x_{n+1}\right)=0 \quad \text { and } \quad \lim _{n \rightarrow+\infty} \Omega\left(g y_{n}, g y_{n+1}, g y_{n+1}\right)=0 .
$$

Using inequality (5), we get

$$
\begin{aligned}
\varphi( & \left.\left(g x_{n}, g x_{n+1}, g x_{n+1}\right)+\Omega\left(g y_{n}, g y_{n+1}, g y_{n+1}\right)\right) \\
= & \varphi\left(\Omega\left(F\left(x_{n-1}, y_{n-1}\right), F\left(x_{n}, y_{n}\right), F\left(x_{n}, y_{n}\right)\right)\right. \\
& \left.+\Omega\left(F\left(y_{n-1}, x_{n-1}\right), F\left(y_{n}, x_{n}\right), F\left(y_{n}, x_{n}\right)\right)\right) \\
\leq & \varphi\left(\Omega\left(g x_{n-1}, g x_{n}, g x_{n}\right)+\Omega\left(g y_{n-1}, g y_{n}, g y_{n}\right)\right) \\
& -\psi\left(\Omega\left(g x_{n-1}, g x_{n}, g x_{n}\right)+\Omega\left(g y_{n-1}, g y_{n}, g y_{n}\right)\right) \\
\leq & \varphi\left(\Omega\left(g x_{n-1}, g x_{n}, g x_{n}\right)+\Omega\left(g y_{n-1}, g y_{n}, g y_{n}\right)\right) .
\end{aligned}
$$

Since $\varphi$ is a nondecreasing function, we obtain

$$
\begin{aligned}
& \Omega\left(g x_{n}, g x_{n+1}, g x_{n+1}\right)+\Omega\left(g y_{n}, g y_{n+1}, g y_{n+1}\right) \\
& \quad \leq \Omega\left(g x_{n-1}, g x_{n}, g x_{n}\right)+\Omega\left(g y_{n-1}, g y_{n}, g y_{n}\right), \quad n \in \mathbb{N}, n \geq 1,
\end{aligned}
$$

that is, $\left(\Omega\left(g x_{n}, g x_{n+1}, g x_{n+1}\right)+\Omega\left(g y_{n}, g y_{n+1}, g y_{n+1}\right)\right)$ is a nondecreasing sequence. Denote by $r \geq 0$ its limit.

Letting $n \rightarrow+\infty$ in relation (6), the continuity of $\varphi$ and the lower semi-continuity of $\psi$ imply

$$
\varphi r \leq \varphi r-\liminf _{n \rightarrow+\infty} \psi\left(\Omega\left(g x_{n}, g x_{n+1}, g x_{n+1}\right)+\Omega\left(g y_{n}, g y_{n+1}, g y_{n+1}\right)\right) \leq \varphi r-\psi r,
$$

which forces $\varphi r=0$, that is, $r=0$. 
Since $\Omega$ takes nonnegative values,

$$
\lim _{n \rightarrow+\infty} \Omega\left(g x_{n}, g x_{n+1}, g x_{n+1}\right)=0 \quad \text { and } \quad \lim _{n \rightarrow+\infty} \Omega\left(g y_{n}, g y_{n+1}, g y_{n+1}\right)=0 .
$$

A similar procedure leads us to

$$
\begin{array}{ll}
\lim _{n \rightarrow+\infty} \Omega\left(g x_{n+1}, g x_{n}, g x_{n}\right)=0, & \lim _{n \rightarrow+\infty} \Omega\left(g y_{n+1}, g y_{n}, g y_{n}\right)=0 ; \\
\lim _{n \rightarrow+\infty} \Omega\left(g x_{n}, g x_{n}, g x_{n+1}\right)=0, & \lim _{n \rightarrow+\infty} \Omega\left(g y_{n}, g y_{n}, g y_{n+1}\right)=0 .
\end{array}
$$

Now, our purpose is to show that

$$
\lim _{m, n \rightarrow+\infty} \Omega\left(g x_{n}, g x_{m}, g x_{m}\right)=0 \quad \text { and } \lim _{m, n \rightarrow+\infty} \Omega\left(g x_{n}, g x_{m}, g x_{m}\right)=0, \quad m>n .
$$

Supposing the contrary, there exist $\varepsilon>0$ and two subsequences $\left(n_{k}\right)$ and $\left(m_{k}\right)$ for which

$$
\begin{aligned}
& \Omega\left(g x_{n_{k}}, g x_{m_{k}}, g x_{m_{k}}\right)+\Omega\left(g y_{n_{k}}, g y_{m_{k}}, g y_{m_{k}}\right) \geq \varepsilon, \\
& \Omega\left(g x_{n_{k}}, g x_{m_{k}-1}, g x_{m_{k}-1}\right)+\Omega\left(g y_{n_{k}}, g y_{m_{k}-1}, g y_{m_{k}-1}\right)<\varepsilon, \quad m_{k}>n_{k} .
\end{aligned}
$$

We obtain

$$
\begin{aligned}
\varepsilon \leq & \Omega\left(g x_{n_{k}}, g x_{m_{k}}, g x_{m_{k}}\right)+\Omega\left(g y_{n_{k}}, g y_{m_{k}}, g y_{m_{k}}\right) \\
\leq & \Omega\left(g x_{n_{k}}, g x_{m_{k}-1}, g x_{m_{k}-1}\right)+\Omega\left(g y_{n_{k}}, g y_{m_{k}-1}, g y_{m_{k}-1}\right) \\
& +\Omega\left(g x_{m_{k}-1}, g x_{m_{k}}, g x_{m_{k}}\right)+\Omega\left(g y_{m_{k}-1}, g y_{m_{k}}, g y_{m_{k}}\right) \\
& <\varepsilon+\Omega\left(g x_{m_{k}-1}, g x_{m_{k}}, g x_{m_{k}}\right)+\Omega\left(g y_{m_{k}-1}, g y_{m_{k}}, g y_{m_{k}}\right) .
\end{aligned}
$$

As $k \rightarrow+\infty$ and $\lim _{n \rightarrow+\infty}\left(\Omega\left(g x_{n}, g x_{n+1}, g x_{n+1}\right)+\Omega\left(g y_{n}, g y_{n+1}, g y_{n+1}\right)\right)=0$, we get

$$
\lim _{k \rightarrow+\infty}\left(\Omega\left(g x_{n_{k}}, g x_{m_{k}}, g x_{m_{k}}\right)+\Omega\left(g y_{n_{k}}, g y_{m_{k}}, g y_{m_{k}}\right)\right)=0
$$

Also, using the properties of $\Omega$, we have

$$
\begin{aligned}
\varepsilon \leq & \Omega\left(g x_{n_{k}}, g x_{m_{k}}, g x_{m_{k}}\right)+\Omega\left(g y_{n_{k}}, g y_{m_{k}}, g y_{m_{k}}\right) \\
\leq & \Omega\left(g x_{n_{k}}, g x_{n_{k}+1}, g x_{n_{k}+1}\right)+\Omega\left(g x_{n_{k}+1}, g x_{m_{k}}, g x_{m_{k}}\right) \\
& +\Omega\left(g y_{n_{k}}, g y_{n_{k}+1}, g y_{n_{k}+1}\right)+\Omega\left(g y_{n_{k}+1}, g y_{m_{k}}, g y_{m_{k}}\right) \\
\leq & \Omega\left(g x_{n_{k}}, g x_{n_{k}+1}, g x_{n_{k}+1}\right)+\Omega\left(g x_{n_{k}+1}, g x_{m_{k}+1}, g x_{m_{k}+1}\right) \\
& +\Omega\left(g x_{m_{k}+1}, g x_{m_{k}}, g x_{m_{k}}\right)+\Omega\left(g y_{n_{k}}, g y_{n_{k}+1}, g y_{n_{k}+1}\right) \\
& +\Omega\left(g y_{n_{k}+1}, g y_{m_{k}+1}, g y_{m_{k}+1}\right)+\Omega\left(g y_{m_{k}+1}, g y_{m_{k}}, g y_{m_{k}}\right) .
\end{aligned}
$$

Taking advantage of the contraction condition, it follows

$$
\begin{gathered}
\varphi\left(\Omega\left(g x_{n_{k}+1}, g x_{m_{k}+1}, g x_{m_{k}+1}\right)+\Omega\left(g y_{n_{k}+1}, g y_{m_{k}+1}, g y_{m_{k}+1}\right)\right) \\
\leq \varphi\left(\Omega\left(g x_{n_{k}}, g x_{m_{k}}, g x_{m_{k}}\right)+\Omega\left(g y_{n_{k}}, g y_{m_{k}}, g y_{m_{k}}\right)\right)
\end{gathered}
$$




$$
\begin{aligned}
& -\psi\left(\Omega\left(g x_{n_{k}}, g x_{m_{k}}, g x_{m_{k}}\right)+\Omega\left(g y_{n_{k}}, g y_{m_{k}}, g y_{m_{k}}\right)\right) \\
\leq & \varphi\left(\Omega\left(g x_{n_{k}}, g x_{m_{k}}, g x_{m_{k}}\right)+\Omega\left(g y_{n_{k}}, g y_{m_{k}}, g y_{m_{k}}\right)\right) .
\end{aligned}
$$

Hence

$$
\begin{aligned}
& \Omega\left(g x_{n_{k}+1}, g x_{m_{k}+1}, g x_{m_{k}+1}\right)+\Omega\left(g y_{n_{k}+1}, g y_{m_{k}+1}, g y_{m_{k}+1}\right) \\
& \leq \Omega\left(g x_{n_{k}}, g x_{m_{k}}, g x_{m_{k}}\right)+\Omega\left(g y_{n_{k}}, g y_{m_{k}}, g y_{m_{k}}\right)
\end{aligned}
$$

and relation (7) becomes

$$
\begin{aligned}
\varepsilon \leq & \Omega\left(g x_{n_{k}}, g x_{n_{k}+1}, g x_{n_{k}+1}\right)+\Omega\left(g x_{n_{k}+1}, g x_{m_{k}+1}, g x_{m_{k}+1}\right) \\
& +\Omega\left(g x_{m_{k}+1}, g x_{m_{k}}, g x_{m_{k}}\right)+\Omega\left(g y_{n_{k}}, g y_{n_{k}+1}, g y_{n_{k}+1}\right) \\
& +\Omega\left(g y_{n_{k}+1}, g y_{m_{k}+1}, g y_{m_{k}+1}\right)+\Omega\left(g y_{m_{k}+1}, g y_{m_{k}}, g y_{m_{k}}\right) \\
\leq & \Omega\left(g x_{n_{k}}, g x_{n_{k}+1}, g x_{n_{k}+1}\right)+\Omega\left(g x_{n_{k}}, g x_{m_{k}}, g x_{m_{k}}\right) \\
& +\Omega\left(g x_{m_{k}+1}, g x_{m_{k}}, g x_{m_{k}}\right)+\Omega\left(g y_{n_{k}}, g y_{n_{k}+1}, g y_{n_{k}+1}\right) \\
& +\Omega\left(g y_{n_{k}}, g y_{m_{k}}, g y_{m_{k}}\right)+\Omega\left(g y_{m_{k}+1}, g y_{m_{k}}, g y_{m_{k}}\right) .
\end{aligned}
$$

For $k \rightarrow+\infty, \lim _{k \rightarrow+\infty}\left(\Omega\left(g x_{n_{k}+1}, g x_{m_{k}+1}, g x_{m_{k}+1}\right)+\Omega\left(g y_{n_{k}+1}, g y_{m_{k}+1}, g y_{m_{k}+1}\right)\right)=\varepsilon$.

The properties of $\varphi, \psi$ lead us to

$$
\begin{aligned}
\varphi \varepsilon & =\lim _{k \rightarrow+\infty} \varphi\left(\Omega\left(g x_{n_{k}+1}, g x_{m_{k}+1}, g x_{m_{k}+1}\right)+\Omega\left(g y_{n_{k}+1}, g y_{m_{k}+1}, g y_{m_{k}+1}\right)\right) \\
& \leq \varphi \varepsilon-\liminf _{k \rightarrow+\infty} \psi\left(\Omega\left(g x_{n_{k}}, g x_{m_{k}}, g x_{m_{k}}\right)+\Omega\left(g y_{n_{k}}, g y_{m_{k}}, g y_{m_{k}}\right)\right) \leq \varphi \varepsilon-\psi \varepsilon .
\end{aligned}
$$

Since $\varepsilon>0$, we obtain a contradiction. Therefore, $\lim _{m, n \rightarrow+\infty} \Omega\left(g x_{n}, g x_{m}, g x_{m}\right)=0$ and $\lim _{m, n \rightarrow+\infty} \Omega\left(g y_{n}, g y_{m}, g y_{m}\right)=0, m>n$.

Analogously, it can be proved that $\lim _{m, n \rightarrow+\infty} \Omega\left(g x_{n}, g x_{n}, g x_{m}\right)=0$ and also

$$
\lim _{m, n \rightarrow+\infty} \Omega\left(g y_{n}, g y_{n}, g y_{m}\right)=0, \quad m>n .
$$

Consider $l>m>n$. Then

$$
\Omega\left(g x_{n}, g x_{m}, g x_{l}\right) \leq \Omega\left(g x_{n}, g x_{m}, g x_{m}\right)+\Omega\left(g x_{m}, g x_{m}, g x_{l}\right) \rightarrow 0 \quad \text { as } n, m, l \rightarrow+\infty .
$$

By Lemma 2.1, we get $\lim _{n, m, l \rightarrow+\infty} \Omega\left(g x_{n}, g x_{m}, g x_{l}\right)=0, l>m>n$. Hence, $\left(g x_{n}\right)$ is a $G$-Cauchy sequence in $g X$, which is complete. Similarly, $\left(g y_{n}\right)$ converges in $g X$. Let $g u=\lim _{n \rightarrow+\infty} g x_{n}$ and $g v=\lim _{n \rightarrow+\infty} g y_{n}, u, v \in X$.

Let us show now that $(u, v)$ is a coupled coincidence point of $F$ and $g$. In that respect, consider $\varepsilon>0$. Since $\left(g x_{n}\right)$ is a Cauchy sequence, then there exists $n_{0} \in \mathbb{N}$ such that for each $n, m, l \geq n_{0}, \Omega\left(g x_{n}, g x_{m}, g x_{l}\right)<\varepsilon$. The properties of lower semi-continuity of $\Omega$ imply

$$
\begin{aligned}
& \Omega\left(g x_{n}, g x_{m}, g u\right) \leq \liminf _{p \rightarrow+\infty} \Omega\left(g x_{n}, g x_{m}, g x_{p}\right) \leq \varepsilon, \\
& \Omega\left(g y_{n}, g y_{m}, g v\right) \leq \liminf _{p \rightarrow+\infty} \Omega\left(g y_{n}, g y_{m}, g y_{p}\right) \leq \varepsilon .
\end{aligned}
$$


Considering $m=n+1$ in (8) and (9), we obtain

$$
\Omega\left(g x_{n}, F\left(x_{n}, y_{n}\right), g u\right)+\Omega\left(g y_{n}, F\left(y_{n}, x_{n}\right), g v\right) \leq 2 \varepsilon .
$$

On the other hand, we get

$$
\begin{aligned}
0 & <\inf \{\Omega(g x, F(x, y), g u)+\Omega(g y, F(y, x), g v): x, y \in X\} \\
& \leq \inf \left\{\Omega\left(g x_{n}, F\left(x_{n}, y_{n}\right), g u\right)+\Omega\left(g y_{n}, F\left(y_{n}, x_{n}\right), g v\right): n \geq n_{0}\right\} \leq 2 \varepsilon,
\end{aligned}
$$

which is a contradiction.

Therefore, $F(u, v)=g u$ and $F(v, u)=g v$.

In the following, we refer to the uniqueness of the coupled coincidence point of $F$ and $g$. Consider $(u, v)$ and $\left(u^{*}, v^{*}\right)$ to be two coupled coincidence points of $F$ and $g$.

By using the contraction condition, we obtain

$$
\begin{aligned}
\varphi & \left(\Omega\left(g u^{*}, g u, g u\right)+\Omega\left(g v^{*}, g v, g v\right)\right) \\
& =\varphi\left(\Omega\left(F\left(u^{*}, v^{*}\right), F(u, v), F(u, v)\right)+\Omega\left(F\left(v^{*}, u^{*}\right), F(v, u), F(v, u)\right)\right) \\
& \leq \varphi\left(\Omega\left(g u^{*}, g u, g u\right)+\Omega\left(g v^{*}, g v, g v\right)\right)-\psi\left(\Omega\left(g u^{*}, g u, g u\right)+\Omega\left(g v^{*}, g v, g v\right)\right) \\
& \leq \varphi\left(\Omega\left(g u^{*}, g u, g u\right)+\Omega\left(g v^{*}, g v, g v\right)\right),
\end{aligned}
$$

which leads us to $\psi\left(\Omega\left(g u^{*}, g u, g u\right)+\Omega\left(g v^{*}, g v, g v\right)\right)=0$, or $\Omega\left(g u^{*}, g u, g u\right)=\Omega\left(g v^{*}, g v, g v\right)=0$.

In a similar manner, we prove that $\Omega\left(g u, g u^{*}, g u\right)=\Omega\left(g v, g v^{*}, g v\right)=0$.

Lemma 2.1 implies that $g u=g u^{*}$ and $g \nu=g v^{*}$.

Having in mind that $g u=F(u, v)$ and $g v=F(v, u)$, we get

$$
\begin{aligned}
\varphi & (\Omega(g u, g v, g v)+\Omega(g v, g u, g v)) \\
& =\varphi(\Omega(F(u, v), F(v, u), F(v, u))+\Omega(F(v, u), F(u, v), F(u, v))) \\
& \leq \varphi(\Omega(g u, g v, g v)+\Omega(g v, g u, g v))-\psi(\Omega(g u, g v, g v)+\Omega(g v, g u, g v)),
\end{aligned}
$$

hence $\psi(\Omega(g u, g v, g v)+\Omega(g v, g u, g v))=0$, or $\Omega(g u, g v, g v)=0$ and $\Omega(g v, g u, g v)=0$. Applying Lemma 2.1, it follows that $g u=g \nu$.

Taking $g=I d_{X}$, the identity mapping, in Theorem 3.3 we obtain a theorem of coupled fixed points.

Corollary 3.3 Consider $(X, G)$ to be a complete G-metric space endowed with an $\Omega$-distance called $\Omega$. Let $F: X \times X \rightarrow X$ be a mapping.

Suppose that there exist $\varphi \in \Phi$ and $\psi \in \Psi$ such that

$$
\begin{array}{r}
\varphi\left(\Omega\left(F(x, y), F\left(x^{*}, y^{*}\right), F\left(z, z^{*}\right)\right)+\Omega\left(F(y, x), F\left(y^{*}, x^{*}\right), F\left(z^{*}, z\right)\right)\right) \\
\leq \varphi\left(\Omega\left(x, x^{*}, z\right)+\Omega\left(y, y^{*}, z^{*}\right)\right)-\psi\left(\Omega\left(x, x^{*}, z\right)+\Omega\left(y, y^{*}, z^{*}\right)\right)
\end{array}
$$

holds for each $(x, y),\left(x^{*}, y^{*}\right),\left(z, z^{*}\right) \in X \times X$. 
Additionally, suppose that if $F(u, v) \neq u$ or $F(v, u) \neq v$, then

$$
\inf \{\Omega(x, F(x, y), u)+\Omega(y, F(y, x), v): x, y \in X\}>0 .
$$

Then $F$ and $g$ have a unique coupled coincidence point $(u, v)$, with $F(u, v)=u=v=F(v, u)$.

Taking $\varphi=i_{[0,+\infty)}$, the identity function, in Theorem 3.3 and Corollary 3.3, we get the following results.

Corollary 3.4 Consider $(X, G)$ to be a G-metric space endowed with an $\Omega$-distance called $\Omega$. Let $F: X \times X \rightarrow X$ and $g: X \rightarrow X$ be two mappings with the properties $F(X \times X) \subseteq$ $g X$, and $g X$ is a complete subspace of $X$ with respect to the topology induced by $G$.

Suppose that there exists $\psi \in \Psi$ such that

$$
\begin{aligned}
& \Omega\left(F(x, y), F\left(x^{*}, y^{*}\right), F\left(z, z^{*}\right)\right)+\Omega\left(F(y, x), F\left(y^{*}, x^{*}\right), F\left(z^{*}, z\right)\right) \\
& \quad \leq \Omega\left(g x, g x^{*}, g z\right)+\Omega\left(g y, g y^{*}, g z^{*}\right)-\psi\left(\Omega\left(g x, g x^{*}, g z\right)+\Omega\left(g y, g y^{*}, g z^{*}\right)\right)
\end{aligned}
$$

holds for each $(x, y),\left(x^{*}, y^{*}\right),\left(z, z^{*}\right) \in X \times X$.

Additionally, suppose that if $F(u, v) \neq$ gu or $F(v, u) \neq g v$, then

$$
\inf \{\Omega(g x, F(x, y), g u)+\Omega(g y, F(y, x), g \nu): x, y \in X\}>0 .
$$

Then $F$ and $g$ have a unique coupled coincidence point $(u, v)$, with $F(u, v)=g u=g v=$ $F(v, u)$.

Corollary 3.5 Consider $(X, G)$ to be a complete $G$-metric space endowed with an $\Omega$-distance called $\Omega$. Let $F: X \times X \rightarrow X$ be a mapping.

Suppose that there exist $\varphi \in \Phi$ and $\psi \in \Psi$ such that

$$
\begin{gathered}
\Omega\left(F(x, y), F\left(x^{*}, y^{*}\right), F\left(z, z^{*}\right)\right)+\Omega\left(F(y, x), F\left(y^{*}, x^{*}\right), F\left(z^{*}, z\right)\right) \\
\leq \Omega\left(x, x^{*}, z\right)+\Omega\left(y, y^{*}, z^{*}\right)-\psi\left(\Omega\left(x, x^{*}, z\right)+\Omega\left(y, y^{*}, z^{*}\right)\right)
\end{gathered}
$$

holds for each $(x, y),\left(x^{*}, y^{*}\right),\left(z, z^{*}\right) \in X \times X$.

Additionally, suppose that if $F(u, v) \neq u$ or $F(v, u) \neq v$, then

$$
\inf \{\Omega(x, F(x, y), u)+\Omega(y, F(y, x), v): x, y \in X\}>0 .
$$

Then $F$ and $g$ have a unique coupled coincidence point $(u, v)$, with $F(u, v)=u=v=F(v, u)$.

Corollary 3.6 Consider $(X, G)$ to be a G-metric space endowed with an $\Omega$-distance called $\Omega$. Let $F: X \times X \rightarrow X$ and $g: X \rightarrow X$ be two mappings with the properties $F(X \times X) \subseteq$ $g X$, and $g X$ is a complete subspace of $X$ with respect to the topology induced by $G$.

Suppose that there exists $k \in[0,1)$ such that

$$
\begin{aligned}
& \Omega\left(F(x, y), F\left(x^{*}, y^{*}\right), F\left(z, z^{*}\right)\right)+\Omega\left(F(y, x), F\left(y^{*}, x^{*}\right), F\left(z^{*}, z\right)\right) \\
& \quad \leq k\left(\Omega\left(g x, g x^{*}, g z\right)+\Omega\left(g y, g y^{*}, g z^{*}\right)\right)
\end{aligned}
$$

holds for each $(x, y),\left(x^{*}, y^{*}\right),\left(z, z^{*}\right) \in X \times X$. 
Additionally, suppose that if $F(u, v) \neq g u$ or $F(v, u) \neq g v$, then

$$
\inf \{\Omega(g x, F(x, y), g u)+\Omega(g y, F(y, x), g \nu): x, y \in X\}>0 .
$$

Then $F$ and $g$ have a unique coupled coincidence point $(u, v)$, with $F(u, v)=g u=g v=$ $F(v, u)$.

Proof The proof follows from Corollary 3.4 by defining $\psi:[0,+\infty) \rightarrow[0,+\infty)$ via $\psi(t)=$ $(1-k) t$.

Corollary 3.7 Consider $(X, G)$ to be a complete G-metric space endowed with an $\Omega$ distance called $\Omega$. Let $F: X \times X \rightarrow X$ be a mapping.

Suppose that there exists $k \in[0,1)$ such that

$$
\begin{aligned}
& \Omega\left(F(x, y), F\left(x^{*}, y^{*}\right), F\left(z, z^{*}\right)\right)+\Omega\left(F(y, x), F\left(y^{*}, x^{*}\right), F\left(z^{*}, z\right)\right) \\
& \quad \leq k\left(\Omega\left(x, x^{*}, z\right)+\Omega\left(y, y^{*}, z^{*}\right)\right)
\end{aligned}
$$

holds for each $(x, y),\left(x^{*}, y^{*}\right),\left(z, z^{*}\right) \in X \times X$.

Additionally, suppose that if $F(u, v) \neq u$ or $F(v, u) \neq v$, then

$$
\inf \{\Omega(x, F(x, y), u)+\Omega(y, F(y, x), v): x, y \in X\}>0 .
$$

Then $F$ and $g$ have a unique coupled coincidence point $(u, v)$, with $F(u, v)=u=v=F(v, u)$.

Proof The proof follows from Corollary 3.5 by defining $\psi:[0,+\infty) \rightarrow[0,+\infty)$ via $\psi(t)=$ $(1-k) t$.

The following example supports our results.

Example 3.1 Take $X=\{0,1,2,3, \ldots\}$. Define $G: X \times X \times X \rightarrow[0,+\infty)$ by the formula

$$
G(x, y, z)= \begin{cases}0 & \text { if } x=y=z \\ x+y+z & \text { if } x \neq y, \text { or } x \neq z \text {, or } y \neq z\end{cases}
$$

Define

$$
\Omega: X \times X \times X \rightarrow X, \quad \Omega(x, y, z)=x+2 \max \{y, z\}
$$

and

$$
T: X \rightarrow X, \quad T x= \begin{cases}0 & \text { if } x=0,1 \\ x-1 & \text { if } x \geq 2\end{cases}
$$

Also, define $\varphi:[0,+\infty) \rightarrow[0,+\infty)$ via $\varphi(t)=t^{2}$ and $\psi:[0,+\infty) \rightarrow[0,+\infty)$ via $\psi(t)=t$. Then:

(1) $(X, G)$ is a complete $G$-metric space.

(2) $\varphi \in \Phi$ and $\psi \in \Psi$. 
(3) $\Omega$ is an $\Omega$-distance function.

(4) If $u \neq T u$, then

$$
\inf \{\Omega(x, T x, u): x \in X\}>0 \text {. }
$$

(5) The following inequality:

$$
\varphi \Omega(T x, T y, T z) \leq \varphi \Omega(x, y, z)-\psi \Omega(x, y, z)
$$

holds for all $x, y, z \in X$.

Proof The proofs of (1) and (2) are clear. To prove part (3), consider $x, y, z, a \in X$. Since

$$
x+2 \max \{y, z\} \leq x+2 a+a+2 \max \{y, z\},
$$

we get

$$
\Omega(x, y, z) \leq \Omega(x, a, a)+\Omega(a, y, z) .
$$

This finishes the proof of the first item of the definition of $\Omega$-distance.

To prove the second item of the definition of $\Omega$-distance, let $x, y \in X$ and $\left(z_{n}\right)$ be any sequence in $X$ converging to $z$ with respect to the topology induced by $G$ in $X$. Thus $z_{n}=z$ for all $n \in \mathbb{N}$ except finitely many terms. Therefore

$$
x+2 \max \left\{y, z_{n}\right\} \rightarrow x+2 \max \{y, x\} \quad \text { as } n \rightarrow+\infty .
$$

So, $\Omega\left(x, y, z_{n}\right) \rightarrow \Omega(x, y, z)$ and hence $\Omega(x, y, \cdot): X \rightarrow[0,+\infty)$ is lower semi-continuous.

Similarly, we can show that $\Omega(x, \cdot, z): X \rightarrow[0,+\infty)$ is lower semi-continuous.

To prove the last item of the definition of $\Omega$-distance, consider $\varepsilon>0$. Take $\delta=\frac{\varepsilon}{2}$. Given $x, y, z \in X$ such that $\Omega(x, a, a) \leq \delta$ and $\Omega(a, y, z) \leq \delta$, by the definition of a $G$-metric space, we have

$$
\begin{aligned}
G(x, y, z) & \leq G(x, a, a)+G(a, y, z) \\
& \leq x+2 a+a+y+z \\
& \leq x+2 a+a+2 \max \{y, z\} \\
& =\Omega(x, a, a)+\Omega(a, y, z) \\
& \leq \varepsilon .
\end{aligned}
$$

This completes the proof of an $\Omega$-distance.

To prove part (4), given $u \in X$ such that $u \neq T u$, then $u \neq 0$. Note that

$$
\begin{aligned}
& \inf \{\Omega(x, T x, u): x \in X\} \\
& \quad \geq \inf \{x+2 u+: x \in X\} \\
& \quad \geq 2 u>0 .
\end{aligned}
$$

To prove part (5), given $x, y, z \in X$, we divide the proof into the following four cases. 
Case 1: $x=y=z=0$. Here, $\Omega(x, y, z)=0$ and $\Omega(T x, T y, T z)=0$. Thus

$$
\varphi \Omega(T x, T y, T z) \leq \varphi \Omega(x, y, z)-\psi \Omega(x, y, z)
$$

Case 2: $x>0$ and $y=z=0$. Here, $\Omega(x, y, z)=x$ and $\Omega(T x, T y, T z)=x-1$. Since $(x-1)^{2} \leq$ $x^{2}-x$, we have

$$
\varphi \Omega(T x, T y, T z) \leq \varphi \Omega(x, y, z)-\psi \Omega(x, y, z)
$$

Case 3: $x=0$ and $y$ or $z$ are not equal to 0 . Without loss of generality, we may assume that $y \geq z$. Thus $y \neq 0$. Here, $\Omega(x, y, z)=2 y$ and $\Omega(T x, T y, T z)=2(y-1)$. Since $4(y-1)^{2} \leq 4 y^{2}-2 y$, we have

$$
\varphi \Omega(T x, T y, T z) \leq \varphi \Omega(x, y, z)-\psi \Omega(x, y, z)
$$

Case 4: $x, y, z$ are all different from 0 . Without loss of generality, we assume that $y \geq z$. Then $\Omega(x, y, z)=x+2 y$ and $\Omega(T x, T y, T z)=x-1+2(y-1)$. Since $(x-1)^{2} \leq x^{2}-x$ and $4(y-1)^{2} \leq 4 y^{2}-2 y$, we have

$$
\begin{aligned}
\varphi \Omega(T x, T y, T z) & =[x-1+2(y-1)]^{2} \\
& =(x-1)^{2}+4(x-1)(y-1)+4(y-1)^{2} \\
& \leq x^{2}-x+4 x y+4 y^{2}-2 y \\
& =(x+2 y)^{2}-(x+2 y) \\
& =\varphi \Omega(x, y, z)-\psi \Omega(x, y, z) .
\end{aligned}
$$

Note that Example 3.1 satisfies all the hypotheses of Theorem 3.1. Thus $T$ has a unique fixed point. Here, 0 is the unique fixed point of $T$.

\section{Competing interests \\ The authors declare that they have no competing interests.}

\section{Authors' contributions}

Both authors contributed equally and significantly in writing this article. Both authors read and approved the final manuscript.

\section{Author details}

${ }^{1}$ Department of Mathematics, Hashemite University, Zarqa, Jordan. ${ }^{2}$ Faculty of Applied Sciences, University Politehnica of Bucharest, 313 Splaiul Independenţei, Bucharest, 060042, Romania.

\section{Acknowledgements}

The authors would like to thank the editor and the referees for their useful comments and remarks.

Received: 8 July 2013 Accepted: 8 October 2013 Published: 08 Nov 2013

\section{References}

1. Mustafa, Z, Sims, B: A new approach to generalized metric spaces. J. Nonlinear Convex Anal. 7(2), 289-297 (2006)

2. Abbas, M, Nazir, T, Radenović, S: Common fixed point of generalized weakly contractive maps in partially ordered G-metric spaces. Appl. Math. Comput. 218(18), 9395-9398 (2012)

3. Aydi, $\mathrm{H}$ : A fixed point result involving a generalized weakly contractive condition in G-metric spaces. Bull. Math. Anal. Appl. 3(4), 180-188 (2011)

4. Aydi, H: A common fixed point of integral type contraction in generalized metric spaces. J. Adv. Math. Stud. 5(1), $111-117(2012)$ 
5. Aydi, H, Karapinar, E, Shatanawi, W: Tripled common fixed point results for generalized contractions in ordered generalized metric spaces. Fixed Point Theory Appl. 2012, 101 (2012)

6. Aydi, H, Karapinar, E, Shatanawi, W: Tripled fixed point results in generalized metric spaces. J. Appl. Math. 2012, Article ID 314279 (2012)

7. Radenović, S, Pantelić, S, Salimi, P, Vujaković, J: A note on some tripled coincidence point results in G-metric spaces. Int. J. Math. Sci. Eng. Appl. 6(VI), 23-38 (2012)

8. Aydi, H, Karapınar, E, Postolache, M: Tripled coincidence point theorems for weak phi-contractions in partially ordered metric spaces. Fixed Point Theory Appl. 2012, ID 44 (2012)

9. Aydi, H, Shatanawi, W, Vetro, C: On generalized weakly G-contraction mapping in G-metric spaces. Comput. Math. Appl. 62(11), 4222-4229 (2011)

10. Gajić, L, Crvenković, ZL: A fixed point result for mappings with contractive iterate at a point in G-metric spaces. Filomat 25(2), 53-58 (2011)

11. Gajić, L, Crvenković, ZL: On mappings with contractive iterate at a point in generalized metric spaces. Fixed Point Theory Appl. 2010, Article ID 458086 (2010)

12. Kaewcharoen, A, Kaewkhao, A: Common fixed points for single-valued and multi-valued mappings in G-metric spaces. Int. J. Math. Anal. 5, 1775-1790 (2011)

13. Tahat, N, Aydi, H, Karapinar, E, Shatanawi, W: Common fixed points for single-valued and multi-valued maps satisfying a generalized contraction in G-metric spaces. Fixed Point Theory Appl. 2012, 48 (2012)

14. Mustafa, Z, Obiedat, H, Awawdeh, F: Some fixed point theorem for mapping on complete G-metric spaces. Fixed Point Theory Appl. 2008, Article ID 189870 (2008)

15. Mustafa, Z, Khandaqji, M, Shatanawi, W: Fixed point results on complete G-metric spaces. Studia Sci. Math. Hung. 48(3), 304-319 (2011)

16. Mustafa, Z, Sims, B: Fixed point theorems for contractive mapping in complete G-metric spaces. Fixed Point Theory Appl. 2009, Article ID 917175 (2009)

17. Mustafa, Z, Shatanawi, W, Bataineh, M: Existence of fixed points results in G-metric spaces. Int. J. Math. Math. Sci. 2009, Article ID 283028 (2009)

18. Öztürk, M, Başarir, M: On some common fixed point theorems with $\phi$-maps on $G$-cone metric spaces. Bull. Math. Anal. Appl. 3, 121-133 (2011)

19. Popa, V, Patriciu, AM: A general fixed point theorem for mappings satisfying an $\phi$-implicit relation in complete G-metric spaces. Gazi Univ. J. Sci. 25(2), 403-408 (2012)

20. Shatanawi, W: Fixed point theory for contractive mappings satisfying $\Phi$-maps in $G$-metric spaces. Fixed Point Theory Appl. 2010, Article ID 181650 (2010)

21. Jeli, M, Samet, B: Remarks on G-metric spaces and fixed point theorems. Fixed Point Theory Appl. 2012, ID 210 (2012)

22. Chandok, S, Mustafa, Z, Postolache, M: Coupled common fixed point theorems for mixed $g$-monotone mappings in partially ordered G-metric spaces. U. Politeh. Buch. Ser. A (in printing)

23. Radenović, S: Remarks on some recent coupled coincidence point results in symmetric G-metric spaces. J. Oper. 2013, Article ID 290525 (2013)

24. Shatanawi, W, Chauhan, S, Postolache, M, Abbas, M, Radenović, S: Common fixed points for contractive mappings of integral type in G-metric spaces. J. Adv. Math. Stud. 6(1), 53-72 (2013)

25. Bhaskar, TG, Laksmikantham, V: Fixed point theorems in partially ordered metric spaces and applications. Nonlinear Anal. 65, 1379-1393 (2006)

26. Laksmikantham, V, Cirić, L: Coupled fixed point theorems for nonlinear contractions in partially ordered metric spaces. Nonlinear Anal. 70, 4341-4349 (2009)

27. Aydi, H, Damjanović, B, Samet, B, Shatanawi, W: Coupled fixed point theorems for nonlinear contractions in partially ordered G-metric spaces. Math. Comput. Model. 54, 2443-2450 (2011)

28. Aydi, H, Postolache, M, Shatanawi, W: Coupled fixed point results for $(\psi, \phi)$-weakly contractive mappings in ordered G-metric spaces. Comput. Math. Appl. 63(1), 298-309 (2012)

29. Choudhury, BS, Metiya, N, Postolache, M: A generalized weak contraction principle with applications to coupled coincidence point problems. Fixed Point Theory Appl. 2013, ID 152 (2013)

30. Chough, R, Rhoades, BE, Agarwal, M: Coupled fixed points of Geraghty-type mappings in G-metric spaces. J. Adv. Math. Stud. 6(1), 127-142 (2013)

31. Cho, YJ, Kadelburg, Z, Saadati, R, Shatanawi, W: Coupled fixed point theorems under weak contractions. Discrete Dyn. Nat. Soc. 2012, Article ID 184534 (2012). doi:10.1155/2012/184534

32. Kadelburg, Z, Nashine, HK, Radenović, S: Common coupled fixed point results in partially ordered G-metric spaces. Bull. Math. Anal. Appl. 4(2), 51-63 (2012)

33. Nashine, HK, Shatanawi, W: Coupled common fixed point theorems for pair of commuting mappings in partially ordered complete metric spaces. Comput. Math. Appl. 62(4), 1984-1993 (2011)

34. Samet, B: Coupled fixed point theorems for a generalized Meir-Keeler contraction in partially ordered metric spaces. Nonlinear Anal. 72, 4508-4517 (2010)

35. Shatanawi, W, Postolache, M: Coincidence and fixed point results for generalized weak contractions in the sense of Berinde on partial metric spaces. Fixed Point Theory Appl. 2013, Article ID 54 (2013)

36. Shatanawi, W: Some common coupled fixed point results in cone metric spaces. Int. J. Math. Anal. 4, 2381-2388 (2010)

37. Shatanawi, W: Coupled fixed point theorems in generalized metric spaces. Hacet. J. Math. Stat. 40(3), 441-447 (2011)

38. Shatanawi, W: Partially ordered cone metric spaces and coupled fixed point results. Comput. Math. Appl. 60 , 2508-2515 (2010)

39. Saadati, R, Vaezpour, SM, Vetro, P, Rhoades, BE: Fixed point theorems in generalized partially ordered G-metric spaces. Math. Comput. Model. 52, 797-801 (2010)

40. Gholizadeh, L, Saadati, R, Shatanawi, W, Vaezpour, SM: Contractive mapping in generalized, ordered metric spaces with application in integral equations. Math. Probl. Eng. 2011, Article ID 380784 (2011)

41. Lakzian, $H$, Aydi, $H$, Rhoades, BE: Fixed points for $(\varphi, \psi, p)$-weakly contractive mappings in metric spaces with w-distance. Appl. Math. Comput. 219, 6777-6782 (2013) 
42. Shatanawi, W, Postolache, M: Some fixed point results for a G-weak contraction in G-metric spaces. Abstr. Appl. Anal. 2012, Article ID 815870 (2012)

43. Shatanawi, W: Some fixed point results for a generalized $\psi$-weak contraction mappings in orbitally metric spaces. Chaos Solitons Fractals 45, 520-526 (2012)

44. Shatanawi, W, Samet, B: On $(\psi, \phi)$-weakly contractive condition in partially ordered metric spaces. Comput. Math. Appl. 62, 3204-3214 (2011)

45. Haghi, RH, Rezapour, S, Shahzad, N: Some fixed point generalizations are not real generalizations. Nonlinear Anal. 74, 1799-1803 (2011)

46. Haghi, RH, Postolache, M, Rezapour, S: On T-stability of the Picard iteration for generalized phi-contraction mappings Abstr. Appl. Anal. 2012, ID 658971 (2012)

10.1186/1687-1812-2013-275

Cite this article as: Shatanawi and Pitea: Fixed and coupled fixed point theorems of omega-distance for nonlinear contraction. Fixed Point Theory and Applications 2013, 2013:275

Submit your manuscript to a SpringerOpen ${ }^{\circ}$ journal and benefit from:

- Convenient online submission

- Rigorous peer review

- Immediate publication on acceptance

Open access: articles freely available online

- High visibility within the field

- Retaining the copyright to your article

Submit your next manuscript at $>$ springeropen.com 